\title{
Profile and Outcome of Diabetic Admissions: A Retrospective Study from Eastern Nepal
}

\author{
Subedi $\mathrm{M}^{1}$, Tripathi $\mathrm{PM}^{2}$, Pradhan $\mathrm{B}^{3}$, Diwedi $\mathrm{S}^{4}$, Bogati $\mathrm{S}^{5}$, Subedi $\mathrm{S}^{6}$, Maskey $\mathrm{R}^{7}$ \\ Assistant Professor ${ }^{1}$, Senior Resident ${ }^{2}$, Professor ${ }^{3}$, Interns ${ }^{4,5,6}$ Addiitonal Professor ${ }^{7}$ \\ ${ }^{1-7}$ Department of Internal Medicine, B.P. Koirala Institute of Health Sciences, Nepal.
}

\begin{abstract}
Introduction: Despite the increasing prevalence of diabetes, lack of awareness about the disease, its consequences and lack of quality care in diabetes lead to delayed presentation to health care giver that might be associated with more number of complication and co-morbid condition of the disease which may adversely affect the outcome of the patient. Therefore we undertook this study to determine the common symptoms that lead to admission of patients suffering from diabetes along with the complications they present and their outcome.
\end{abstract}

Methods: We analyzed data from the medical records available among admitted patients with diabetes over a period of 6 months.

Results: Among 200 subjects with mean age of 52 years, majority had Type 2 diabetes mellitus, 53\% were males and more than half had some other comorbidities. Most of them, $68 \%$ had microvascular complications, and $27 \%$ of them had some form of macrovascular complications.

Conclusions: Despite of continuous effort from various organizations, micro and macrovacular complications are very high among diabetic patients, so more emphasis has to be given on prevention of these complications at various level of health care delivery system.

Key Words: diabetes, microvascular, Nepal

\section{Introduction}

Diabetes mellitus is a group of metabolic disease characterized by hyperglycemia resulting from defects in insulin secretion, insulin action, or both. Estimates show a global prevalence of 382 million people with diabetes in 2013, expected to rise to 592 million by $2035^{1}$. Diabetes is estimated to have resulted in 1.5 to 3.7 million deaths per year worldwide ${ }^{2}$. Nepal is also seeing the increasing prevalence of diabetes similar to neighbouring countries in South asia ${ }^{3}$.

Corresponding author

Dr. Manish Subedi, MD,

Assistant Professor, Department of Internal Medicine B.P. Koirala Institute of Health Sciences, Dharan, Nepal drsubedimanish@gmail.com, manish.subedi@bpkihs.edu Phone: 0097725525555 (Extension: 2052)

Fax Number: 0097725520251
The prevalence of diabetes in Nepal is reported to be $9.5 \%{ }^{4}$ and Nepal Diabetes Association reports that among people aged 20 years and older living in urban areas, $15 \%$ are affected by this disease, among people aged 40 years and older in urban areas $19 \%$ are affected ${ }^{5}$. Despite the increasing prevalence of diabetes lack of awareness about the disease, its consequences and lack of quality care in diabetes lead to delayed presentation to health care giver that might be associated with more number of complication and co-morbid condition of the disease which may adversely affect the outcome of the patient.

Therefore we undertook this study to determine1) common symptoms that lead to admission of patients suffering from diabetes, 2) common 
complications associated with diabetes and 3) outcome of patients.

\section{METHODS}

This was a hospital based retrospective study in which the diabetic patients admitted at the Medicine ward of B.P. Koirala Institute of Health Sciences (BKIHS) for a period of 6 months were enrolled. After ethical clearance from the Institutional Ethical Review Board data was obtained from the records register in the Medicine ward which included demographic characteristics, presenting symptoms, co-morbidities, complications, previous treatment, duration of hospital stay and outcome of the patient.

\section{RESULTS}

Table 1: Baseline Characteristics of the Patient enrolled in the study $(n=200)$

\begin{tabular}{|l|l|}
\hline Age (Mean in yrs) & $52(22-82)$ \\
\hline Sex (Male \%) & $53 \%$ \\
\hline$\%$ of patients > 50 years of age & $56 \%$ \\
\hline Type of Diabetes Mellitus (\%) & \\
Type 1 & $7 \%$ \\
Type 2 & $93 \%$ \\
Others & $0 \%$ \\
\hline Family history of diabetes in at least & \\
one parents (\%) & $9 \%$ \\
\hline Smoker (\%) & $43 \%$ \\
\hline Alcohol consumer (\%) & $58 \%$ \\
\hline Co-morbidities & \\
None & $48 \%$ \\
Hypertension & $25 \%$ \\
\hline Duration of diabetes in years (\%) & \\
\hline$<10$ years & $63 \%$ \\
$10-20$ years & $34 \%$ \\
\hline 20 years & $25 \%$ \\
\hline Treatment modality (\%) & $18 \%$ \\
Dietary and lifestyle modification alone & $45 \%$ \\
\hline OHA and dietary modification & \\
Insulin and dietary modification & \\
Insulin, OHA and dietary modification & \\
\hline
\end{tabular}

The mean age group of our study population was 52 years and the gender distribution revealed slight male predominance with $53 \%$ patients male. Majority of patients $(56 \%)$ belonged to age group $>50$ years and $93 \%$ were affected by type 2 DM. About $43 \%$ of our Patients were smokers, $58 \%$ of our patients consumed alcohol and only 9\% revealed family history of diabetes in at-least one parent. Hypertension was the most common comorbidity associated which was seen in $25 \%$ of patients.

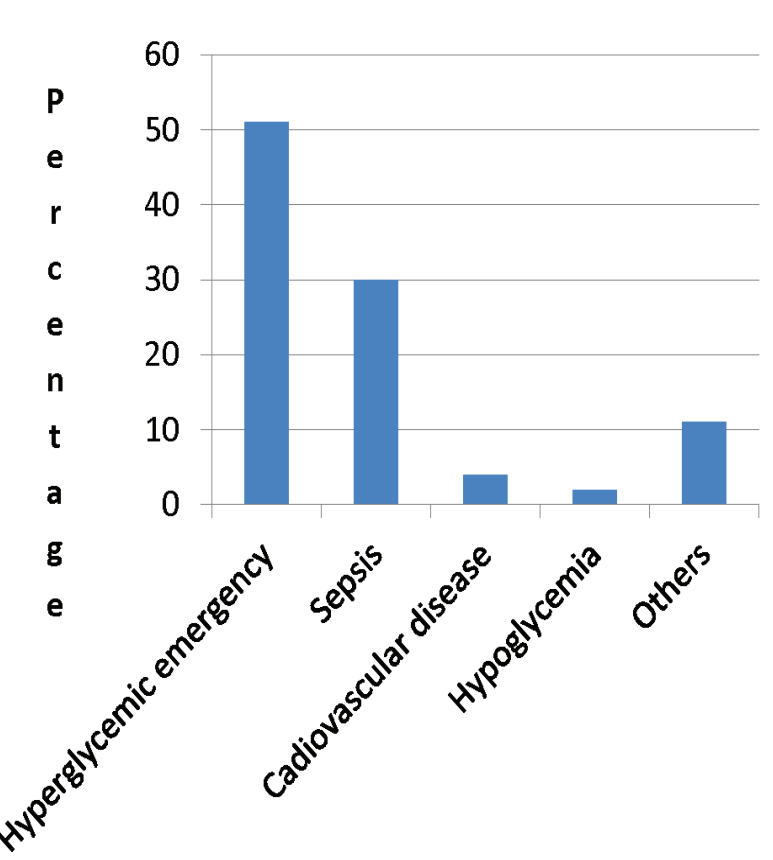

Reason for admission

Figure 1: Reason for admission among patients enrolled $(n=200)$

Hyperglycemic emergency (51\%) was the major cause of admission of the patients in our study. It was followed by sepsis $(30 \%)$, cardiovascular disease $(6 \%)$, hypoglycemia (2\%) and others (11\%). 
Table 2: Complications present at the time of admission among patients enrolled in the study $(\mathrm{n}=\mathbf{2 0 0})$

\begin{tabular}{|l|r|}
\hline Complications & Percentage $(\mathrm{n}=200)$ \\
\hline Micro-vascular complications & $68 \%$ \\
Nephropathy & $21 \%$ \\
Neuropathy & $10 \%$ \\
Retinopathy & $8 \%$ \\
Nephropathy and Retinopathy & $9 \%$ \\
Nephropathy and Neuropathy & $7 \%$ \\
Neuropathy and Retinopathy & $3 \%$ \\
All three & $10 \%$ \\
\hline Macro-vascular complications & $27 \%$ \\
Cardio-vascular disease & $20 \%$ \\
Peripheral vascular disease & $4 \%$ \\
Both & $3 \% \%$ \\
\hline
\end{tabular}

In our study population, $68 \%$ of the patients were affected by micro vascular complications of which nephropathy was the most common (21\%) followed by neuropathy (10\%) and retinopathy (8\%). 10\% had all the three micro vascular complications. Similarly, $27 \%$ of them were affected by macro vascular complication of $(20 \%)$ had CardioVascular and $4 \%$ had Peripheral Vascular Disease and $3 \%$ had both.

\section{Outcome of patients}

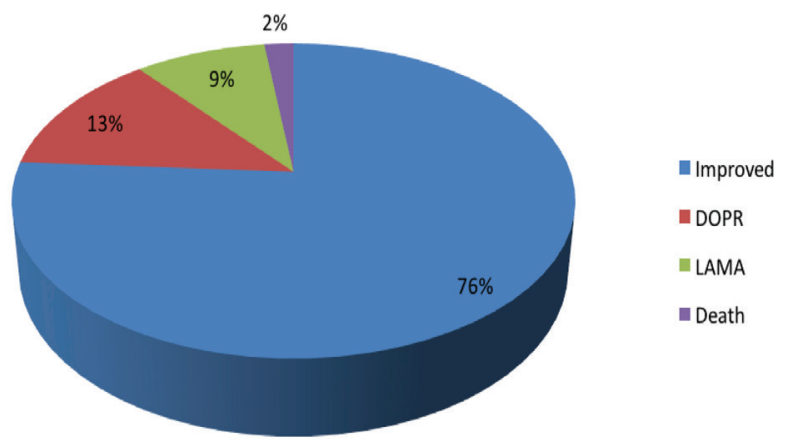

Figure 2: Outcome of the patient $(n=200)$

Among the study population, the mean duration of hospital stay was $6.2 \pm 3.8$ days. Majority (76\%) of the patients improved at the time of discharge, 13\% were discharged on request, $9 \%$ left against medical advice, $2 \%$ died at the hospital. Out of the 4 deaths ( $2 \%), 2$ patients died due to End stage Renal disease, 1 patient had acute Coronary Syndrome and 1 patient died due to sepsis secondary to pneumonia.

\section{DISCUSSION}

The mean age of diabetic patients presenting to the hospital with complications or symptoms was 52 years and majority of the patients (56\%) were more than 50 years of age which is consistent with previous studies ${ }^{6,7,8}$. Our study shows relatively high rate of diabetes mellitus in male $(53 \%)$ compared to female $(47 \%)$, which was similar to results shown in studies conducted in Nepal ${ }^{8,9}$ but a study conducted in Europe showed an increased prevalence in females ${ }^{10}$. This difference may be related to more health seeking behavior of male in our society.

Though Type 2 Diabetes Mellitus has a strong genetic component ${ }^{11,12,13,14}$ and $39 \%$ of patients with type 2 diabetes have at least one parent with the disease ${ }^{15}$ only $9 \%$ patients in our study had family history of diabetes in at least one of parents. This difference could be attributed to lack of diagnostic ability due to limited health resources in the preceding decades.

Hypertension was the most common co-morbidity associated with diabetes in this study which was present only in $25 \%$ of patients which is not consistent with previous studies which showed that prevalence of hypertension is $40-70 \%$ in diabetic patients $16,17,18$. This difference could be due to the fact that majority of patients included presented with hyperglycemic emergency and sepsis which resulted in lower blood pressure measurements.

In this study $43 \%$ patients were smokers and as smoking aggravates the micro- and macro-vascular complications of diabetes mellitus and is associated with insulin resistance ${ }^{19,20}$ smoking cessation can have greater public health implications for the reduction of morbidity and mortality due to complications of diabetes especially in our 
population. Also increased prevalence of smoking could be one of the contributing factors majorities of patients presented with hyperglycemic emergency owing its effect on insulin resistance.

Majority of the cases accounting for the Diabetic admissions were related to hyperglycemic emergency (51\%) which included Diabetic ketoacidosis (DKA) and hyperglycemic hyper osmolar state (HHS) which was followed by sepsis $(30 \%)$, cardiovascular disease $(6 \%)$, and hypoglycemia (2\%). The frequency of hyperglycemic emergency is far more than that obtained from a study conducted at Malaysia ${ }^{21}$. This might be due to lack of proper awareness about glycemic control in our society and increased frequency of smoking in our study population. Also hypoglycemia was seen to be a common cause of hospitalization in this study probably because of high percentage of alcohol consumer $(58 \%)$ in our study population.

This study shows prevalence of micro-vascular complications- retinopathy to be $30 \%$, neuropathy $30 \%$ and nephropathy $47 \%$ and prevalence of macrovascular complications-Cardiovascular Disease $23 \%$ and Peripheral Vascular Disease $7 \%$ which are consistent with the international trends ${ }^{22,23,24}$. In comparisons regarding the prevalence of diabetic micro vascular complications, the study shows that the prevalence of diabetic nephropathy is more than neuropathy and retinopathy. This may be because the patients in the current study have hypertension which is related to renal complications. In addition, the population in this study is Asian, where the prevalence of nephropathy is more than the other people ${ }^{25}$.

The mean duration of hospital stay in our study population was 6.2 days which was similar to a study conducted in Pakistan 6. Out of the 200 patients admitted $(76 \%)$ of the patients improved at the time of discharge, $13 \%$ were discharged on request, $9 \%$ left against medical advice, $2 \%$ died at the hospital. End Stage Renal disease and Cardiovascular disease were the most common cause of mortality in our study which is consistent with worldwide trends ${ }^{26,27}$.

Our study had several limitations. First it was a retrospective hospital based study which is subjected to numerous biases. Also the duration of diabetes and occurrence of diabetic complications were not co-related.

\section{CONCLUSIONS}

Diabetes Mellitus is a significant cause for medical admission at BPKIHS. Majority of the diabetic patients who were admitted at medicine ward had symptoms related to complications of Diabetes (both acute and chronic). The lack of proper diabetic care and the lack of awareness about diabetes and its complications might have contributed to this. Based on this study we recommend frequent screening for micro-vascular and macro-vascular complications of diabetes and frequent blood glucose monitoring to prevent hyperglycemic emergency.

\section{Conflict of interest}

None

\section{REFERENCES}

1) Gandhi NF, Wareham NJ, "Epidemiology of diabetes" Medicine (Abingdon). 2014 Dec; 42(12): 698-702.

2) World Health Organization. WHO; Global report on diabetes. 2016

3) Ono K, Limbu YR, Rai SK, Kurokawa M, Yanagida $\mathrm{J}$, Rai G, et al. The prevalence of type 2 diabetes mellitus and impaired fasting glucose in semi-urban population of Nepal. Nepal Med Coll J. 2007;9:154-6.

4) M. Adak, S. Nazri. Risk factors assessment for Type-II Diabetes Mellitus 14 Journal of Institute of Medicine, December, 2008; 30:3 23-30

5) Poudel RR, " Diabetes and Endocrinology in Nepal" Indian J Endocrinol Metab. 2014 Jan-Feb; 18(1): 118-119.doi: 10.4103/2230-8210.126593

6) Patel M, Patel IM etal, "A Hospital-based Observational Study of Type 2 Diabetic Subjects from Gujarat, India" J Health Popul Nutr. 2011 Jun; 29(3): 265-272.

7) Tarin SMA, Khan MI, "Pattern of diabetic admissions in medical ward", Pakistan J. Med. Res. Vol. 43 No.4, 2004.

8) Singh NK, Shah NK etal, "Presentations and 
complications of diabetes patients presenting to diabetic clinic of Eastern Nepal, Journal of College of Medical Sciences-Nepal : Vol 9, No 3, 25-30 (2013)

9) Dinesh K Upadhyay, Subish Palaian, P. Ravi Shankar, Pranaya Mishra. Knowledge, Attitude and Practice about Diabetes among Diabetes Patients in Western Nepal. Rawal Med J 2008;33:8-11

10) Fleming DM, Schellevis FG, Casteren VV. The prevalence of known diabetes in eight European countries. European Journal for Health 2004:14:1

11) John E. Gerich. The Genetic Basis of Type 2 Diabetes Mellitus. Endocrine Reviews 19 (4): 491-503

12) Paulsen EP, Richenderfer L, Ginsberg-Fellner F. Plasma glucose, free fatty acids and immunoreactive insulin in sixty-six obese children: studies in reference to a family history of diabetes mellitus. Diabetes $1968 ; 17: 261-269$

13) Lemieux S, Despres J, Nadeau A, Prud'homme D, Trembloy A, Bouchard C. Heterogenous glycemic and insulinemic responses to oral glucose in nondiabetic men: interactions between duration of obesity, body fat distribution and family history of diabetes mellitus. Diabetologia1992; 35:653-659

14) Migdalis I, Zachariadis D, Kalogeropoulou K, Nounopoulos C, Bouloukos A, Samartzis M. Metabolic abnormalities in offspring of NIDDM patients with a family history of diabetes mellitus. Diabet Med 1996;13:434-440

15) Klein BE, Klein R, Moss SE, Cruickshanks KJ. Parental history of diabetes in a population-based study. Diabetes Care 1996; 19:827.

16) Turner, RC; Holman, RR, etal. "Prevalence of Hypertension in newly presenting type- 2 diabeticpatients and the association with risk-factors for Cardiovascular and Diabetic complications". J HYPERTENS , 11 (3) 309 - 317

17) Kabakov E1, Norymberg $\mathrm{C}$ etal, "Prevalence of hypertension in type 2 diabetes mellitus: impact of the tightening definition of high blood pressure and association with confounding risk factors".J Cardiometab Syndr. 2006 Spring;1(2):95-101.

18) Moore WV1, Fredrickson D etal, "Prevalence of hypertension in patients with type II diabetes in referral versus primary care clinics". J Diabetes Complications. 1998 Nov-Dec;12(6):302-6

19) Sang Ah Chang," Smoking and Type 2 Diabetes Mellitus". Diabetes Metab J. 2012 Dec; 36(6): 399403.

20) Xi-tao Xie, Qiang Liu, Jie Wu, Makoto Wakui, " Impact of cigarette smoking in type 2 diabetes development. Acta Pharmacol Sin. 2009 Jun; 30(6): 784-787

21) Unadike BC, Essien I etal, "Profile and Outcome of Diabetic admissions at the University of Uyo Teaching Hospital, Uyo". International Journal of Medicine and Medical sciences, Vol5(6), 286-289

22) Al-Maskari F, El-Sadig, " Prevalence of diabetic retinopathy in the United Arab Emirates: a crosssectional survey". BMC Ophthalmology20077:11

23) Abougalambou SS etal,"Current Clinical Status and Complications among Type 2 Diabetes patient in University sains Malaysia hospital". International journal of Diabetes Mellitus 2(2010),184-188

24) Tesfaye S, Stevens L etal, "Prevalance of diabetic neuropathy and its relation to glycemic controland potential risk factors, The EURODIAB IDDM complication study". Diabetologia 1996;39:1377-84

25) KennethA. Earle Kamilla K. Porter Julia Ostberg John S. Yudkin," Variation in the progression of diabetic nephropathy according to racial origin". Nephrology Dialysis Transplantation 2001:16(2):286-290

26) Baena-Díez JM etal." Risk of Cause-Specific Death in Individuals With Diabetes: A Competing Risks Analysis .Diabetes Care 2016 Nov; 39(11): 19871995

27) Meiying Zhu, Jiang Li,etal." Mortality rates and the causes of death related to diabetes mellitus in Shanghai Songjiang District: an 11-year retrospective analysis of death certificates".BMC Endocr Disord. $2015 ; 15: 45$ 